\title{
SLURS AND SEMANTIC INDETERMINACY
}

\author{
Giuliano Torrengo \\ University of Milan, Autònoma University of Barcelona \\ penultimate version, to appear in Philosophia
}

February 4, 2020

\begin{abstract}
The analysis of the derogatory aspect of slurs has recently aroused interest among philosophers of language. A puzzling element of it is its erratic behaviour in embeddings, for instance negation or belief reports. The derogatory aspect seems sometimes to "scope out" from the embedding to the context of utterance, while at other times it seems to interact with the linguistic constructions in which the slur is implanted. I argue that slurs force us to maintain a kind of semantic indeterminacy which, to my knowledge, has passed largely unnoticed in philosophy of language.
\end{abstract}

Keywords: Slurs · Expressives · Indeterminacy · Semantic Deference

\section{The Derogatory Aspect of Slurs}

Slurs are pejoratives that convey an offense toward a targeted class of people, what I will call a derogatory aspect. If we consider the language of homophobes or racists, it is not difficult to find examples of derogatory epithets that target groups, which are individuated by their ethnicity or sexual preferences. However, rather than resorting to actual examples from homophobic or racist speech, I stipulate that any occurrence of ' $S$ ' in what follows will stand for a slur, and any occurrence of ' $C$ ' will stand for the neutral counterpart of $S$, that is a term that has the same extension as $\mathrm{S}$, but does not possess derogatory aspecit. Slurs are often offensive regardless of whether they are used to insult some individual(s) in particular - as in (1) - or not - as in (2).

\footnotetext{
${ }^{1}$ If there is no neutral counterpart, $\mathrm{C}$ will stand for a non-derogatory description of the class. I am not assuming here that having a neutral counterpart is a distinguishing feature of slurs (see Ashwell (2016)). Many authors agree that slurs have neutral counterparts usually (see Nunberg 2018) for some reflections on this aspect of slurs).
} 
(1) He is a $S$

(2) Ss are good people

The analysis of the derogatory aspect of slurs has recently aroused interest among philosophers of language. A puzzling element of it is its erratic behavior in embeddings, for instance negation or belief reports. The derogatory aspect seems sometimes to "scope out" from the embedding to the context of utterance, while at other times it seems to interact with the linguistic constructions in which the slur is implanted. For instance, in (3) the negation does not seem to affect the offensiveness with respect to the targeted group $\mathrm{C}$ elicited by the slur S, but in (4) it seems to interact with the derogatory aspect $\mathrm{S}$.

(3) There are no Ss in this show

(4) He is not a $\mathrm{S}$, he is a $\mathrm{C}$

Roughly speaking, in the literature about slurs we find three kinds of approach. According to the strict content approach, the derogatory aspect of slurs is determined by the semantic conventions governing them - i.e., the rules that give their literal meaning. According to this approach, their derogatory aspect is part of their truth-functional content; hence, it interacts with embedding structures in normal ways $\mathrm{s}^{2}$. The no-content approach denies that any offensive content is conveyed by the utterance of a slur. Thus, the semantic content of a slur $\mathrm{S}$ is no different from the semantic content of its neutral counterpart $\mathrm{C}$; what makes it offensive to use the former expression is the presence, in our society, of a convention concerning the admissible uses of the former but not of the latter ${ }^{3}$ Since the conventions responsible for the offensiveness of slurs concern what words the speaker is allowed to use, the derogatory aspect always scopes out to the context of use. The broad content approach considers the derogatory aspect as a sort of lateral content, and puts it in the area of presuppositions or conventional implicature. Such a content does not normally affect the truthconditions of the statement, but it is still "lexicalized", in that it is not conveyed merely in virtue of general pragmatic factors. According to this approach, slurs have an offensive content, because they signal a negative and hostile attitude on the part of the utterer toward the targeted group. This expressive and evaluative content is automatically conveyed by the use of the expression; it is not

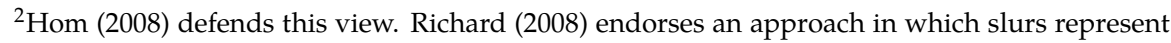
their target in a negative way, but the kind of representation involved is not truth-apt. Hornsby (2001) sketches a view in which the derogatory aspect is part of the meaning but has an expressive ("gestural") dimension. Croom (2014) provides arguments against pure "expressivist" understanding of the derogatory component of slurs.

Anderson \& Lepore 2013, Feinberg 1985, who endorse the view that it is a censorial or taboo convention; Predelli [2010] holds that the convention is about the subjective admissibility of use.
} 
cancelable in the way that what is conversationally implicated usually is, but it is separable from the truth-functional content (which it is for the most part shared by the neutral counterparts $]_{4}^{4}$ in that it easily scopes out of the linguistic contexts in which slurs can be embedded 5

Each approach makes distinctive predictions about the behavior of slurs in embeddings. However, defenders of the strict content strategy and defenders of the no-content and broad content strategies also disagree on whether the data confirm the predictions or not. Pre-theoretical intuitions here seem to be hard to pin down. Although I will argue that such a conflict of intuition is indeed characteristic of slurs, I will not defend the thesis that slurs are ambiguous expressions. Rather, I argue that slurs force us to maintain a kind of semantic indeterminacy which, to my knowledge, has passed largely unnoticed in philosophy of language. Roughly, the semantic conventions concerning slurs leaves it indeterminate whether by using a slur a speaker is stating a negative content concerning the targeted group, or is signaling a hostile and negative attitude toward them. Although other expressions may to some extent be subject to the same phenomenon of falling in between a descriptive dimension and an expressive one, among pejoratives (such as swearwords and insults), slurs typically display such an indeterminacy. In providing a hypothesis on the origin of the derogatory aspect of slurs, I will also sketch an account of why, given certain social and historical conditions, slurs display this indeterminacy.

\footnotetext{
${ }^{4}$ The relation between the truth-functional content of a slur $S$ and its neutral counterpart $C$ is a complex question, and different version of the broad content approach treat it differently. If the denigratory aspect is conveyed through a conventional implicature (cf. Williamson (2009)), then the $S$ and $C$ have the same truth-functional content. If the denigratory aspect is conveyed through a presupposition, the truth-functional content of $S$ coincides with that of $C$ only if we consider cases in which the presupposition is satisfied. According to subject-oriented versions of the presuppositional account, the presupposition is about the attitude of the speaker (i.e., the speaker despises the target group) and it is therefore "self-fulfilled" (cf. Schlenker 2007) and the truth-conditional contents of $\mathrm{S}$ and $\mathrm{C}$ are - de facto - the same. According to object-oriented versions of the presuppositional account, the presupposition is about the target group itself (i.e., the target group is despicable). Given the stereotypical nature of the derogation conveyed the presupposition will fail, and and the truth-conditional contents of S and C are - de facto - different (cf. Cepollaro 2015) and Cepollaro \& Stojanovic (2016)).

"Williamson (2009), Potts 2007), Schlenker 2007). Separability is what Potts calls "nondisplaceability". While separability can be seen as an essential feature of conventional implicatures (Potts 2005. Chap. 5); Hom (2012. 177)), it is widely accepted that certain linguistic contexts (e.g. conditionalization) can act as plugs for presuppositions and block the scoping out phenomenon. However, "expressive" presuppositions are much less easily plugged (Maciá (2011); Schlenker (2007). See Richard 2008, 18-22) for arguments that the derogatory aspect of slurs is not a conversational presupposition. Also, as will become clear below, metalinguistic occurrences (i.e. quotative utterances) can block the scoped out reading.
} 


\section{Scoping-out}

Slurs in embeddings sometimes behave as if their derogatory aspect were part of the descriptive content that they linguistically signify, and at other times as if they expressed a negative attitude of the speaker toward the targeted group Both readings seem to be admissible in most cases (if not all) but there is wide disagreement about what the preferred reading should be (if indeed there is one). How do the three approaches that I have outlined account for such instability? Both the no-content approach and the broad content approach deny that there are uses of slurs that fail to convey an offense toward the targeted group 7 as seems to be the case in the default reading of (4).

(4) He is not a $\mathrm{S}$, he is a C

Of course, (4) can be read meta-linguistically, as saying that ' $\mathrm{S}$ ' is not a term to be used in order to refer to C; but cases like (5) are more difficult treat in this way.

(5) Institutions that treat Cs as Ss should be sanctioned

For the same reason, both strategies deny that by someone uttering (6) can easily attribute the offensive aspect to Mick, since the preferred reading is the one in which it is the speaker who is insulting Cs. 8

(6) Mick thinks that John is a S

\footnotetext{
${ }^{6}$ An analogous dichotomy of behavior between pejorative nouns and verbs on the one side and pejorative adjectives and adverbs on the other is discussed in Hom (2012), who acknowledges a "diversity of conflicting intuitions" (p.8).

Anderson \& Lepore 2013 - in defending a form of no-content approach - have argued that in appropriated uses (such as the in-group use of slur terms among Afro-Americans) no offense is conveyed toward the targeted group, because appropriated uses are allowed by defeasible escape clauses to the censorial convention. Here I am not considering appropriated uses, because my focus is the semantic behaviour of slurs under embedding, when they are used in standard contexts. Appropriated uses are often interpreted as uses in which a change of meaning, or an attempt to change of meaning takes place (see Richard (2008, 9), and Hom 2008, 428)). Even if that is wrong (as Anderson \& Lepore (2013) argues), and although the idea of a standard context is hard to pin down (especially with respect to "problematic words" such as slurs), appropriated uses are derivatives ones. That is not to say that theory on the semantic behaviour of slurs will have eventually to provide an account of appropriated uses too, I am just claiming that restriction to non-appropriated uses is methodologically useful here.

${ }^{8}$ There may be differences here between the no-content approach and the broad content approach. It is difficult to read an utterance of (6) as accusing Mick to have broken a convention concerning " $\mathrm{S}$ ", that is a reading in which the derogatory aspect does not scopes out. However, at least certain version of the presuppositional account predict that in reports the denigratory effect is diminished (cf. Cepollaro, Sulpizio, \&Bianchi (2019)).
} 
And the same should hold for (7), in which case it is even more problematic to deny that the preferred reading does not convey that Mick has a negative stance towards the targeted group (i.e. he is - depending on the slur - either a homophobe, or a racist, or...).

\section{(7) According to Mick, John is a S}

There are, of course, various strategies for the defender of the no-content or broad content approaches to cope even with the most recalcitrant data: for instance, by pointing out that (5) also has a meta-linguistic flavor 19 or by insisting that even (7) can be used without conveying the idea that Mick is slurring the $\mathrm{C}^{10}$ However, it seems to me that at least some of the data show that the derogatory aspect connected with slurs can interact with embedding structures at the level of content, and that any position that denies this has to cope with a non-trivial amount of recalcitrant data.

The strict content approach does no better. The scoping-out effect connected to slurs is a pervasive phenomenon. As noted above, in (3) the derogatory content is not negated.

(3) There are no Ss in this show

Besides, even if the preferred reading of (6) is the one in which the utterer is attributing the slur to Mick, there are readings that are compatible with the utterer expressing a slur and the hearer knowing (or believing) that Mick is not slurring the Cs. Another problematic case is embedding in tense. It is doubtful that who used to have negative stances toward a targeted group can refer to the group by using a slur $S$ as in (8) without running the risk of now expressing a slur against them.

(8) I used to think that Ss were despicable people

Again, various strategies can be used to explain the scoping-out effect without abandoning the idea that slurs offend in virtue of their truth-functional meaning. However - as with its rival view - any position which denies that

\footnotetext{
${ }^{9}$ As Predelli (2010) suggests, although he does not provide a explicit meta-linguistic reading of it. Cepollaro \& Thommen (2019) elaborates on the thesis in more detail.

"See Anderson \& Lepore 2013), who claim also to be "suspicious" of most of the data concerning acceptable uses of slurs in embedding structures. Another problem for those approaches is to account for the difference between pairs of sentences like "All Cs are Cs" and "All Cs are Ss". I will not take these into account here, because they are not crucial to my main point.
} 
the "scoping out" reading is sometimes the default one has to explain away a large amount of recalcitrant dat: ${ }^{11}$

My intuitions with respect to the default readings of claims such as (3) to (8) are not clear-cut, and I suspect that that is how things should be. Accepting that there are expressive lexemes whose preferred reading is normally the "scoping out" one (e.g., "damn"), and descriptive lexemes, whose preferred reading is one that interacts with the embedding construction (e.g., "damned"), slurs do not seem to fit into either category ${ }^{12}$. My hypothesis is that the linguistic conventions that ground the derogatory meaning of slurs leave it undetermined whether the derogatory content is part of the truth-functional meaning or whether it qualifies the evaluative attitude of the speaker. Thus, although there is a robust regularity connecting the use of slurs and the conveying of a derogatory aspect with respect to a targeted group, how such regularity is conventionalized as part of the meaning of a slur is undetermined. Whatever determines the semantic content of a slur $\mathrm{S}$ leaves it open whether $\mathrm{S}$ has a derogatory truth-functional content, or is merely associated with the expression of a derogatory and hostile attitude of the speaker. Note that I am not defending the view that slurs are ambiguous, or polysemous, in the sense that they can acquire both an expressive reading and a descriptive reading, and require a pragmatic disambiguation in order to be (contextually) assigned a determinate semantic value. According to my proposal, pragmatic phenomena do not intervene at the semantic or pre-semantic level; rather, in any context the semantic content is undetermined, and thus the derogatory aspect of slurs is neither part of their truth-functional content nor a separable element.

\section{The Origin of the Derogation}

In order to spell out my thesis, I will focus on the explanation of the origin of the derogatory aspect of slurs. The no-content strategy explains offensiveness in terms of conventions concerning the admissible behavior for the users of language. On Anderson \& Lepore (2013)'s version of the approach, the offensiveness arises from a censorial convention to the effect that any use of slurs is a taboo. Whoever breaks the convention shows disrespect for the taboo and thereby elicits the derogatory aspect of the slur. In this version at least, the

\footnotetext{
${ }^{11}$ Hom 2012) admits that the "orthodox" behavior of slurs (and pejorative nouns in general) is the wide scope one, but he maintains that it is due to Gricean implicatures calculated from the literal meaning of what is said. He seems to maintain that, generally speaking, unsung a predicate $\mathrm{P}$ conversationally implicate that $\mathrm{P}$ has non-empty extension; and that is what generates offensiveness.

${ }^{12}$ The outline of the distinction between the expressive and the descriptive dimensions of meaning can be found in Kaplan (ms.). For examples of couple of terms, which are very close in meaning, but of which one behave like a descriptive term, the other like an expressive, see Predelli [2010].
} 
no-content explanation of the origin of the derogatory aspect is not convincing. Firstly, taboos about words seem to exist because of the offensive content expressed or conventionally conveyed by the slurs, rather than the other way around ${ }^{13}$. Secondly, what makes it the case that ' $S$ ' is the taboo word rather than ' $C$ '? The no-content view cannot appeal to a difference in descriptive or expressive content between the two expressions, since by assumption there is none. Hence, if we explain the derogatory aspect of ' $S$ ' in terms of the mere breaking of a taboo, we are compelled to leave it as a brute fact that ' $\mathrm{S}$ ' is a taboo word, while ' $C$ ' is not. Of course, sooner or later we need to arrive at brute facts to explain linguistic conventions. However, I will argue below that there is a further story about the offensive aspect of slurs that we can convincingly tell.

The strict content approach explains the derogatory aspect in terms of conventions concerning its truth-functional meaning. On Hom (2008)'s version of the strict content approach, the offensive aspect of slurs is given by the fact that there are social institutions that support an ideology and a set of practices against certain groups of people. For instance, racial epithets about AfricanAmericans (or other ethnical groups) get their meaning from social institutions of racism against African-Americans (or other ethnical groups), which embody both an ideology comprising (usually negative) beliefs concerning the targeted group, and a set of discriminatory practices (the ideology is often used to justify the normative aspect of the practices). I maintain that the broad outline of Hom's externalist account of what determines the derogatory content conveyed by slurs is correct. The main problem with the account is that even if the presence of a derogatory institution is a sufficient condition (together with facts about the use of the slur in question) for the slur to have a derogatory aspect, it is not a necessary one ${ }^{14}$ My hypothesis is that the derogatory aspect of slurs comes from the presence of widespread derogatory stances in society toward the groups of people that the slurs target. Derogatory stances are to be understood as negatively colored emotional attitudes shared by "communities" of people (e.g. homophobes, racists) with respect to the targeted group. Although the mere membership of the targeted group is usually sufficient to elicit the negative attitude, people of the "community" often have convergent descriptive beliefs about the stereotypical features of the members of the targeted group, and share evaluative beliefs about them. At least in cases where the hostility of the community sharing the derogatory stance is strong, the descriptive aspect and the normative aspect connected to the derogatory stance support and justify each other. For instance, homophobes typically believe that (i) homosexuals exemplify a certain stereotype, and (ii) they are therefore to be denigrated

\footnotetext{
${ }^{13}$ For a similar critique to Anderson \& Lepore (2013), see Jeshion (2013b). See also Camp (2013).

${ }^{14}$ Jeshion 2013b objects to Hom that there does not have to be an institution with specific discriminatory practices and ideology in order for a slur to possess a derogatory content, and she offers counterexamples.
} 
and discriminated against $t^{\sqrt{15}}$ Thus, derogatory stances shared by communities of people can give rise to "institutions" (in the terminology of Hom (2008)) supporting and enacting discriminatory practices toward a targeted group, although they do not need to reach a full fledged institutional level to have an effect on the semantics of certain terms.

The stance of homophobes (like that of the racist, the sexist, and so on) concerns the world and not meaning, but certain words are typically perceived as characteristic of homophobes ${ }^{16}$ Consider a slur $\mathrm{S}$ that homophobes use to refer to homosexuals. Of course, the neutral counterpart of $S$, "homosexual", too is in a sense a negative term to the homophobe, because it describes sexual behaviors he (or she) disapproves of. However, a homophobe who does not know that using "homosexual" in a non-homophobic context would not be perceived as expressing a negative attitude against the homosexual, whereas using ' $\mathrm{S}$ ' would, is lacking competence in English (and the same is true of a non-homophobe).

This is my hypothesis on the relevance of the presence in society of such derogatory stances for the semantics of slurs. The connection between the derogatory stance shared by a certain community and the ordinary meaning of slurs can be seen in analogy to the mechanism of deference (Putnam 1975). Ordinary uses of terms used by scientific communities are cases of deferred uses. The fact that in our societies there are experts with respect to, for instance, botany, makes it the case that when I use the word "elm", although I know little about the differences between elms and beeches, I am deferring to the botanic experts with respect to the capacity of distinguishing between these two kinds of tree. In a sense, my use of "elm" or "beech" expresses what their use expresses. In the case of scientific terms, the mechanism of deference seems to be mediated by the speaker's intentions, but this is not essential to the picture. The mechanism through which what the speaker expresses is determined by what the experts express is triggered by the very presence, in the relevant social context, of experts using the word in question in certain ways, and not by the speaker's specific intention to use them in a deferred way. By analogy, the presence in the

\footnotetext{
${ }^{15} \mathrm{Cf}$. Blackburn's notion of "stance" and its link with descriptive and normative beliefs (Blackburn (1993)). Williamson (2009) makes reference to a stereotype in connection with slurs. See also Jeshion (2013a). I think the notion of a "slurring perspective" endorsed by Camp (2013) is closely related to the idea of a derogatory stance that I am developing here.

${ }^{16}$ See also Saka (2007): "For in order to believe that a pejorative applies to someone, one must have not only contempt for a certain class but also access to conventionally established pejorative terminology; one must belong to a linguistic community in which pejoratives exist. Since the conventionalization of contempt relies, like all convention, on societally recognized norms, every pejorative utterance is proof not only of the speaker?s contempt, but proof that such contempt prevails in society at large. This is why pejoratives make powerful insults, why repeated exposures to pejoratives can create feelings of alienation, inferiority, and self-hatred, and indeed why a single pejorative utterance evokes measurable bias in overhearers" (p. 142).
} 
society of homophobes who use $\mathrm{S}$ to denigrate homosexuals makes it the case that in ordinary contexts $\mathrm{S}$ has a derogatory meaning independently of the intention of the speaker. In our society, $\mathrm{S}$ is a term characteristic of homophobes, and whoever uses it in an ordinary context runs the risk of conveying a homophobic content 17

However, the derogatory meaning that slurs acquire from the existence in society of a "community" of homophobes using it does not need to be part of the truth-functional content - as the strict content approach maintains. Indeed, the derogatory stances, although often connected to "thicker" descriptive and normative elements, are in the first place emotional attitudes toward other groups of people. At least in the version that I have sketched above, the general outline of the externalist explanation of the origin of the derogatory aspect is compatible with the broad content view of the convention concerning slurs, and also with the no-content approach, since both the semantic rules that concern separable contents and rules concerning admissibility of uses can be explained in terms of the stances of certain communities in the societies. Leaving aside for now the question of whether the derogatory aspect is part of the strict semantic content, or whether it is a form of separable content, or whether it derives from rules of use admissibility, the fact that uses of slurs convey a derogatory meaning with respect to the targeted group is better explained by the presence of derogatory stances in the society than by sheer taboo conventions ${ }^{18}$. Such an account of the origin of the derogatory aspect of slurs is also compatible with the hypothesis regarding their peculiar form of semantic indeterminacy. The generally perceived connection between a slur $\mathrm{S}$ and the stance of homophobes or racists (say) determines certain linguistic conventions. But whether the linguistic conventions are such that the derogatory content is part of the truthfunctional content expressed by literal uses of the term and thus a descriptive element of meaning (something that a speaker states by uttering a slur), or a separable element that signals a derogatory attitude of the speaker and thus an

\footnotetext{
${ }^{17}$ Although I am not considering an account of appropriated uses here, I suspect that a correct account of appropriation, too, should follow the line of Hom (2008)'s remarks: if racists and homophobes have the role of "experts" with respect to slurs, in order to appropriate a slur - whether in its in-group use or its out-group one - the semantic connection between the slur and the "experts" must be receded or drastically modified.

${ }^{18}$ In so far as Andersen and Lepore's explanation of the origin of the derogatory content differs from Hom's, they cannot endorse the further explanatory step and explain the taboo norms in terms of the derogatory stances. However, there is nothing as such in the no-content position (i.e. the thesis that the derogatory aspect comes from the convention concerning the admissibility of the use of slurs) that clashes with taking this further step. Note that broad content approaches are compatible with explanations of the origin of the derogatory content in terms of no-content, depending on how much the mechanism of conveying the derogatory content is seen as a meaningrelated convention. Williamson 2009) points out that the truth-conditional contents of a slur and of its neutral counterpart are the same. However, he also insists that a slur is not synonymous with its neutral counterpart.
} 
expressive element (something that is not stated, but signals a hostile attitude) depends on the linguistic data concerning its behavior in embeddings. As I have argued, the linguistic conventions are undetermined with respect to the status of the derogatory content of slurs. If I am right, slurs have a semantic content that is constitutively in between an expressive dimension and a descriptive dimension; they have a truth-functional component that they share with their neutral counterpart, and an undetermined derogatory component.

The semantic indeterminacy of slurs bear a closer resemblance to that of vague terms, such as "bald", rather than to that of ambiguous terms, such as "bank" - assuming that something like the semantic account of vagueness (rather than the epistemic one) is true. The semantic value of "bald" does not coincide with any of its precisifications, because the linguistic conventions fall short of determining one of them as the semantic value of the term, and thus in any context "bald" has a vague semantic content. Analogously, the linguistic conventions for a slur $\mathrm{S}$ fall short of settling whether their derogatory component is part of the strict content, or a separable element. The analogy is only partial, because in the case of vague terms, the indeterminacy concerns uniquely the extension of a term, whereas in the case of slurs, if I am right, the indeterminacy concerns more generally the semantic nature of their derogative aspects 19 Indeed, I am not claiming that slurs are vague words, I claim that slurs display a peculiar kind of semantic indeterminacy; one that, to my knowledge, has passed largely unnoticed in philosophy of languag $\mathrm{e}^{20}$.

\section{Slurs and Politically Correct Language}

Now, the fact that a slur $\mathrm{S}$ is semantically undetermined in the sense just specified makes it the case that if we aim to establish a determined conveyed meaning of a certain utterance of ' $S$ ', much will depend on how we construe the stance of the speaker. In particular, if it is clear from the context that there is an intention to insult the targeted group, it will be more natural to construe it as if it were an expressive term, which always scopes out. For instance, even an ironic use of a slur $\mathrm{S}$ for homosexuals, in the mouth of someone we assume to be homophobic, will be easily seen as conveying a derogatory content. Imagine

\footnotetext{
${ }^{19} \mathrm{As}$ an anonymous referee has pointed out, the extension is also touched by this indeterminacy, since whether the derogatory content of $\mathrm{S}$ counts as lexical or not has radical consequences for the extension of $\mathrm{S}$. If it is, its extension is empty (no one is $\mathrm{C}$ and despicable in virtue of being $\mathrm{C}$ ); if it is not, $\mathrm{S}$ and $\mathrm{C}$ have the same extension.

${ }^{20}$ On semantic vagueness see Varzi [2007). Notice that here I am only exploiting the theory of vagueness as semantic indeterminacy for a (partial) analogy, but my position does not require that such a particular theory of vagueness is true. Also, I am taking precisifications as possible interpretations of the language. If you read them as possible languages, then the last line should read Ò... does not coincide with the semantic value of any of its precisifications...Ó.
} 
homophobes calling ironically a particularly masculine friend of theirs a S. If the irony is apparent, they may not even be insulting him, while still insulting homosexuals. Whereas, if the context makes it clear that the speaker has no intention of insulting the targeted class, it is more natural to construe the expressions as if were endowed with a derogatory meaning, which can interact truth-functionally with other semantic and pragmatic devices. The semantic indeterminacy leaves open the question of whether the semantic content does or does not contain a derogatory component, and if we look for a definite answer, it is not surprising that the plausibility of one hypothesis or the other is influenced by the attitude that we attribute to the speaker (with respect to the target group, rather than with respect to the person, if any, she is addressing). However, strictly speaking neither hypothesis is correct: the semantic content of the slur is undetermined in any context, in the sense that it is neither determinately part of the content nor determinately a separable element.

Therefore, the intentions of the speaker do not have the role of a contextual disambiguating element here, as if slurs possessed an indexical element sensitive to it. The hypothesis that slurs possess such an indexical element is difficult to reconcile with the censorial "aura" that typically surrounds them, especially in public contexts. If the intended attitude of the speaker with respect to the targeted group were sufficient to disambiguate the semantic role of the derogatory aspect of slurs, non-atomic occurrences of them (e.g. within the scope of negation or a verb of attitude) in contexts where the lack of hostility of the speaker with respect to the targeted group is apparent would always be read by default as non-offensive with respect to the targeted group. But, as I have argued above, the intuitions of competent speakers with respect to the acceptability of such uses are often unstable. This is why institutional or semi-institutional censorship (a "politically correct language only" policy) on basically all uses of slurs is justified, in so far as it is morally unacceptable to discriminate against people on the grounds of their ethnicity, sexual orientation, and the like. Moral principles cannot per se justify censorship on words, but by appealing to the deference mechanism we can explain why a word used by a community of people who share a derogatory stance is prohibited throughout the wider linguistic community. If slurs possessed an indexical element sensitive to the intention of the speaker, in contexts in which the intentions of the speaker are apparent (and the slur is embedded in negation or report), the censorship would be unjustified. But the derogatory element is inherited by the wider linguistic community independently of the intentions of the speaker. And although the semantic role of the derogatory element is undetermined by the linguistic conventions, a competent speaker is aware that making evident his or her non-hostile intentions with respect to the targeted group is not enough to elicit a permissible use of slur (even if embedded). 
Thus, although I have rejected the explanation of the origin of the derogatory stance in terms of taboo convention, the indeterminacy hypothesis is not incompatible with the presence of taboos, but only with the thesis that the breaching of the censorship explains the derogatory aspect. I agree that the fact that even in contexts where the semantic content is neutralized, such as explicit mentions in quotes, uses of slurs can easily still be offensive, as explained by the censorial convention. However, even clearly descriptive terms, which usually do not scope out, can be subjected to taboo when the descriptive content is for some reason socially unacceptable. In other words, derogatory stances are at the origin both of the derogatory meaning of slurs and of the censorial conventions regarding them, which originate because and in so far as the derogatory aspect is regarded as discriminatorily unjustified. The thesis of indeterminacy, besides accounting for the conflict of intuitions concerning the co-presence of descriptive and expressive occurrences of slurs, also provides reasons for regarding the censorial convention as justified, without understanding it as a brute fact, as Anderson \& Lepore (2013)'s version of the no content view sees it. In so far as the expressive reading is always a living option which cannot easily be ruled out, a prohibition on basically all the uses of the word, especially in the public context, can be seen as part of a general disapproval of derogatory stances and of discrimination against the targeted group.

\section{References}

Anderson, L. \& Lepore, E. (2013), 'Slurring Words', Noûs 47: 25-48

Ashwell, L. (2016) ‘Gendered slurs,' Social Theory and Practice 42 (2): 228-239

Blackburn, S. (1993), Essays in Quasi-Realism, New-York, Oxford University Press.

Cepollaro, B. (2015) 'In defence of a presuppositional account of slurs,' Language Sciences 52: 36-45

Cepollaro, B. \& Stojanovic I. (2016) 'Hybrid evaluatives: in defense of a presuppositional account.', Grazer Philosophische Studien 93 (3): 458-488

Cepollaro, B., Sulpizio, S. \& Bianchi C. (2019). 'How bad is it to report a slur? An empirical investigation.', Journal of Pragmatics 146: 32-42.

Cepollaro, B. \& Thommen, T. (2019) 'What's wrong with truth-conditional accounts of slurs.', Linguistics and Philosophy (online first)

Camp, L. (2013), 'Slurring Perspectives', Analytic Philosophy 54 (3): 330-349 
Croom, A.M. (2014), 'The Semantics of Slurs: A Refutation of Pure Expressivism', Language Sciences 41, 227-242.

Feinberg, J. (1985), Offense To Others, Oxford University Press, Oxford.

Hom, C. (2008), 'The Semantics of Racial Epithets', Journal of Philosophy 105: $416-440$

Hom, C. (2012), 'A Puzzle about Pejoratives', Philosophical Studies 159 (3): 383406

Hom, C. \& May, R. (2013), 'Moral and Semantic Innocence', Analytic Philosophy 54 (3): 293-313

Hornsby, J. (2001), 'Meaning and Uselessness: How to think about derogatory words', Midwest Studies in Philosophy: Figurative Language 25: 128-141

Predelli, S. (2010), in Sawyer, S.A., ed. New Waves in Philosophy of Language, Palgrave-MacMillan, pp. 164-185.

Predelli, S. (2013), Meaning Without Truth, New-York, Oxford University Press.

Putnam, H. (1975), 'The meaning of" meaning"', Minnesota Studies in the Philosophy of Science 7: 131-193

Jeshion, R. (2013a), 'Slurs and Stereotype', Analytic Philosophy 54 (3): 314-329

Jeshion, R. (2013b), 'Expressivism and the Offensiveness of Slurs', Philosophical Perspectives 27 (1): 231-259

Kaplan, D. (ms.), 'The Meaning of 'Ouch' and 'Oops".

Maciá, J. (2011), 'A defense of the presuppositional view of expressive meaning' (hand-out for the ECAP-7 conference in Milan).

Nunberg, G. (2018), 'The Social Life of Slurs'?, in Fogal, Daniel, Harris, Daniel and Moss, Matt (eds.), New Work on Speech Act, Oxford, Oxford University Press

Potts, C. (2005), The Logic of Conventional Implicature, Oxford University Press, Oxford.

Potts, C. (2007), 'The Expressive Dimension', Theoretical Linguistics: 165-197

Richard, M. (2008), When Truth Gives Out, Oxford University Press, Oxford.

Saka, P. (2007) How to think about meaning, Springer

Schlenker P. (2007), 'Expressive Presuppositions', Theoretical Linguistics 33 (2): 237-245 
Varzi, A. (2007), 'Supervaluationism and Its Logics', Mind 116: 633-676

Williamson, T. (2009), in Almog, J. \& Leonardi, P., eds. 'The Philosophy of David Kaplan', Oxford University Press, Oxford, pp. PPP-PPP. 